\title{
Medical Countermeasures Analysis of 2019-nCoV and Vaccine Risks for Antibody- dependent Enhancement (ADE)
}

\author{
Darrell O. Ricke, $\mathrm{PhD}^{1}$ \& Robert W. Malone ${ }^{2}, \mathrm{MD}$ \\ ${ }^{1}$ Biological and Chemical Technologies \\ Massachusetts Institute of Technology Lincoln Laboratory \\ Lexington, MA USA \\ ${ }^{2}$ Chief Medical Officer, Alchem Laboratories \\ 13305 Rachel Boulevard, Alachua FL 32615 USA \\ rmalone@alchem.com \\ ORCID: 0000-0003-0340-7490
}

Corresponding author: Darrell O. Ricke, Ph.D.

Email: Darrell.Ricke@11.mit.edu

ORCID for Darrell Ricke is 0000-0002-2842-2809

\section{Summary}

Background In $80 \%$ of patients, COVID-19 presents as mild disease ${ }^{1,2} .20 \%$ of cases develop severe $(13 \%)$ or critical (6\%) illness. More severe forms of COVID-19 present as clinical severe acute respiratory syndrome, but include a T-predominant lymphopenia ${ }^{3}$, high circulating levels of proinflammatory cytokines and chemokines, accumulation of neutrophils and macrophages in lungs, and immune dysregulation including immunosuppression ${ }^{4}$.

Methods All major SARS-CoV-2 proteins were characterized using an amino acid residue variation analysis method. Results predict that most SARS-CoV-2 proteins are evolutionary constrained, with the exception of the spike (S) protein extended outer surface. Results were interpreted based on known SARS-like coronavirus virology and pathophysiology, with a focus on medical countermeasure development implications.

Findings Non-neutralizing antibodies to variable S domains may enable an alternative infection pathway via Fc receptor-mediated uptake. This may be a gating event for the immune response dysregulation observed in more severe COVID-19 disease. Prior studies involving vaccine candidates for $\mathrm{FCoV}^{5,6} \mathrm{SARS}-\mathrm{CoV}-1^{7-10}$ and Middle East Respiratory Syndrome coronavirus (MERS-CoV) ${ }^{11}$ demonstrate vaccination-induced antibody-dependent enhancement of disease (ADE), including infection of phagocytic antigen presenting cells (APC). T effector cells are believed to play an important role in controlling coronavirus infection; pan-T depletion is present in severe COVID-19 disease ${ }^{3}$ and may be accelerated by APC infection. Sequence and structural conservation of $S$ motifs suggests that SARS and MERS vaccine ADE risks may foreshadow SARS-CoV-2 S-based vaccine risks. Autophagy inhibitors may reduce APC infection and T-cell depletion $^{12}{ }^{13}$. Amino acid residue variation analysis identifies multiple constrained domains suitable as $\mathrm{T}$ cell vaccine targets. Evolutionary constraints on proven antiviral drug targets present in SARS-CoV-1 and SARS-CoV-2 may reduce risk of developing antiviral drug escape mutants. 
Interpretation Safety testing of COVID-19 S protein-based B cell vaccines in animal models is strongly encouraged prior to clinical trials to reduce risk of ADE upon virus exposure.

\section{Introduction}

COVID-19 is caused by the SARS-CoV-2 (2019-nCoV) betacoronavirus. The SARS-CoV-2 is a novel betacoronavirus with sequenced genomes ranging from $29.8 \mathrm{k}$ to $29.9 \mathrm{k}$ RNA bases. The SARS-CoV-2 genome encodes replicase proteins, structural proteins, and accessory proteins ${ }^{14}$ (Table 1). The ORF1a and ORF1ab polyproteins are proteolytically cleaved into 16 nonstructural proteins designated nsp1-16 ${ }^{14}$ (Table 1). Like SARS, COVID-19 manifests as a virulent zoonotic virus-mediated disease in humans with currently 81,191 confirmed cases and 2,768 deaths as of Feb. 26, $2020^{15}$.

Zoonotic MERS-CoV, SARS-CoV-1, and SARS-CoV-2 are evolutionarily related, and share many similarities in human disease characteristics and progression. The mild variant first phase of viral progression generally presents with mild flu-like symptoms. Most patients never progress beyond this phase, and typically recover quickly and uneventfully. In a mouse animal model, phagocytic cells contribute to the antibody-mediated elimination of SARS-CoV- ${ }^{16}$, and it may be that innate responses are sufficient to suppress MERS-CoV and SARS-CoV-2 in the majority of patients. For some individuals $\left(18.5 \%{ }^{17}\right)$, infection progresses to a second severecritical variant phase. Progression to the second phase often coincides with the typical timing of onset of adaptive humoral immunity antibody response (approximately 7-14 days post infection). MERS-CoV can infect monocyte-derived macrophages (MDMs), monocyte-derived dendric cells (MoDCs), and T-cells ${ }^{18,19}$, but the infectivity of SARS-CoV-2 in these cell populations (with or without non-neutralizing antibody) has not been characterized. For patients with severe and critical symptoms, the pathophysiology is consistent with increased infection of phagocytic immune cells (immature MDMs and MoDCs); see Figure 1 for a diagram of the postulated cascade mechanism. Chemokines released from infected cells may attract additional dendritic cells and immature macrophages that are susceptible to infection, leading to a possible infection amplifying cascade of immune cell infection and dysregulation. For some patients with severe symptoms, excessive activation of macrophages may contribute to a chemokine and cytokine storm $^{20-22}$. Individuals with SARS have pronounced peripheral T-cell lymphocytopenia with reduced $\mathrm{CD}^{+}$and $\mathrm{CD}^{+}{ }^{+}$-cells ${ }^{23,24}$, just as is observed with COVID-193. MERS-CoV and SARS-CoV are also associated with T-cell apoptosis ${ }^{25,26}$. Infection of macrophages and some Tcells along with viral dysregulation of cellular pathways result in compromised innate and humoral immunity in patients during this second and more severe phase of infection ${ }^{27}$. High virus titer in blood plus the possibility of infected immune cell migration throughput the body may account for the additional disease pathophysiologic and clinical observations observed with these viruses. MHC I and interleukin (IL)-12 receptor B1 (IL-12RB1) genetic differences associated with disease progression has been characterized for SARS ${ }^{28-30}$. Patients with low or deficient serum levels of the innate immune response pattern recognition molecule mannosebinding lectin (MBL) have increased frequency in SARS patients versus controls ${ }^{31}$. MHC downregulation by epigenetic modifications seen with MERS-CoV infections may enhance avoidance of T-killer cell responses, and direct infection of some T-cells ${ }^{18}$ may play a role in increased mortality rate seen for MERS ${ }^{32}$. Other disease differences may simply be the different population of cells with target host receptors angiotensin I converting enzyme 2 (ACE2) for 
SARS-CoV-1 and SARS-CoV-2 ${ }^{33}$, and dipeptidyl peptidase IV (DPP4) for MERS-CoV. ACE2 is expressed in high density in lungs ${ }^{34}$.

Characterizing variability and evolution of viral proteins must inform medical countermeasure (MCM) design and development strategies for RNA viruses such as SARS-CoV-2. For viral progeny, deleterious mutations are rapidly selected against $\mathrm{t}^{35}$. Neutral mutations ${ }^{36}$ provide a framework for antigenic drift to facilitate escape from immune responses; these residues will continue to mutate over time. The critical-spacer model proposes that proteins have either amino acid residue side-chains critical for function or have variable side-chains which may function for positioning/folding of critical residues ${ }^{37}$. The divergence model of protein evolution proposes that the number of critical residues for a protein is consistent for evolutionarily closely related proteins ${ }^{38}$. Herein, these concepts are applied to SARS-CoV-2 proteins by leveraging closely related coronavirus protein sequences to provide insights into viral vulnerabilities that can be exploited when designing MCMs. The majority of the SARS-CoV-2 proteins exhibit very high proportions of critical residues to total residues (see Table 2 and Figure 2); hence, these viral enzymes are excellent small molecule targets. Such small molecule drug therapeutics or prophylactics have good chances of being effective against SARS-CoV, SARS-CoV-2, and SARS-like CoVs if they target these highly conserved domains. Non-exposed replicase and accessory proteins have abundant highly conserved long peptide targets for selecting continuous segments of critical residues for T-cell epitope vaccines ${ }^{39}$. In contrast, the extracellular domain of the $\mathrm{S}$ protein exhibits exposed surface areas with high amino acid residue variability. Increased risk for antibody-dependent enhancement (ADE) from vaccines targeting SARS-CoV2, SARS-CoV-1, and MERS-CoV exposed residues is indicated by observed ADE in animal models and the antibody facilitated infection of phagocytic immune cells frequently observed with coronaviruses ${ }^{16,40}$. Peptides and antibodies targeting HR2 and cell fusion have been shown to block SARS-CoV-1 and MERS-CoV infections in cell lines ${ }^{41-47}$ and animal models ${ }^{48-50}$. Based on the conservation of these domains observed with divergence-based modeling, testing of similar peptides and antibodies to these targets for SARS-CoV-2 may yield new insights and opportunities for MCM development. Likewise, drugs that target the phagocytic pathway associated with Fc-receptor mediated endocytosis are promising candidates for blocking the cascade of immune cell infections that results in immune dysregulation in COVID-19 patients.

\section{Methods}

2019-nCoV protein sequences from GenBank entry MN908947.3 were searched against the nonredundant (nr) and PDB database using the NCBI BLASTP web interface. Hit protein sequences were downloaded. Protein multiple sequence alignments were created with the Dawn program ${ }^{51}$. Additional 2019-nCoV sequences were added to existing alignments with the Jalview program ${ }^{52}$. Identified protein structures were downloaded from RCSB PDB database ${ }^{53}$. Dawn variation results were visualized with the Jmol program $^{54}$.

\section{Role of the funding source}

The funder of the study had no role in study design, data collection, data analysis, data interpretation, or writing of the report. The corresponding authors had full access to all the data in the study and had final responsibility for the decision to submit for publication. 


\section{Results}

Dawn variation results for 2019-nCoV amino acid residues were classified into residues with no observed variability (candidate critical residues; colored dark green in Figure 2) and to residues with 5 or more amino acid substitutions (candidate spacer residues; colored dark blue in Figure 2). Amino acids residues colored yellow are considered constrained, allowing only a subset of possible amino acid substitutions. Amino acid residues with conservative substitutions are also considered critical residues, and are colored light green in Figure 2; positions with $>95 \%$ conservation of a single residue were included in this category to accommodate potential sequencing errors and possible adaptative mutations. Twelve of the nsp replicase proteins have a ratio of critical to total residues of 0.9 or higher (Table 1); this is illustrated in Figure 2 for 2019$\mathrm{nCoV}$ proteins with high proportions of critical residues in Figure 2 (dark green residues). In sharp contrast, the $\mathrm{S}$ protein exhibits regions of extensive variability of exposed surface residues (Figure 2).

\section{Discussion}

\section{Variation Results}

The observed amino acid variations in SARS-CoV-2 proteins are consistent with expected natural variations in the context of random mutations and selection in the context of host immune responses. For the nonstructural replicase proteins, the majority have fractions of critical residues above $88 \%$ (Table 2 ). Long continuous stretches of invariant residues are excellent candidates for T-cell vaccines epitope selection, and also for exploratory anti-viral small inhibitory RNA (siRNAs) ${ }^{55}$ development. With a large RNA genome, the virus has evolved over time by deleting unnecessary spacer residues. The S protein $\mathrm{S} 1$ extended domain shows the highest number of exposed surface highly variable residues, in sharp contrast to the replicase enzymes (Figure 2). These spacer residues may function as exposed antigens for antibody responses with the possible adaptive benefit of suppressing immune responses to less immunogenic surface antigens. Many of these S protein antigens may lead to non-neutralizing antibodies. Alternately, evolutionary selection for mutations to these residues may facilitate antigenic drift to escape immune responses. It seems unusual to have the excessive number of spacer residues on the S1 extended domain, unless it provides 2019-nCoV with an additional selective advantage associated with non-neutralizing antibodies bound to this domain.

\section{Coronaviruses have Multiple Options for Cell Infection}

The 2019-nCoV S protein contains receptor-binding domains (RBD) targeting human angiotensin I converting enzyme 2 (ACE2) ${ }^{56,57}$; this is the initial route for infecting host cells. To take advantage of antibody responses, coronaviruses also leverage antibody Fc uptake to infect immune cells ${ }^{58}$. Coronaviruses use the $\mathrm{S}$ protein subunit $2 \mathrm{FP}, \mathrm{HR} 1$, and HR2 to infect immune cells upon proteolytic cleavage of $\mathrm{S}$ within endosomes. HR1 and HR2 form a canonical 6 -helix bundle involved in membrane fusion ${ }^{41}$. Jaume et al. ${ }^{58}$ found that antibody-mediated infection was dependent on Fc receptor II and not the endosomal/lysosomal pathway utilized by ACE2 targeting. Viral infection of complement receptor (CR) cells is an additional possible route of infecting cells ${ }^{59}$. This multi-pronged approach provides coronaviruses like SARS-CoV1, MERS-CoV, and SARS-CoV-2 with more than one mechanism for infecting host cells. This leads to the hypothesis that antibody mediated uptake of virus is the potential mechanism that 
induces ADE to vaccines and can also be mediated by maternally transferred antibodies $(\text { matAbs })^{60-63}$.

\section{Macrophages and Immune Dysregulation}

Lymphopenia is a common feature in patients with SARS ${ }^{23,64}$ or COVID-19 ${ }^{65,66}$. Two receptors have been identified for SARS-CoV-1 including ACE2 ${ }^{67}$ and C-type lectin domain family 4 member M (CLEC4M, CD209L, CD299, DC-SIGN2, DC-SIGNR, HP10347, and L-SIGN) ${ }^{68}$ with CLEC4M expressed in human lymph nodes ${ }^{69}$. Individuals homozygous for CLEC4M tandem repeats are less susceptible to SARS infection ${ }^{70}$. In a mouse model, depletion of CD4+ T cells resulted in an enhanced immune-mediated interstitial pneumonitis when challenged with SARS-CoV-1 ${ }^{71}$. In contrast, depletion of CD4+ and CD8+ T cells as well as antibodies enabled innate defense mechanisms to control the SARS-CoV-1 virus without immune dysregulation ${ }^{71}$. Similar results were also observed in mice with SARS-CoV-1 challenge, but treatment with liposomes containing clodronate, which deplete alveolar macrophages (AM), prevented immune deficient virus-specific $\mathrm{T}$ cell response ${ }^{72}$. In a macaque model, anti-spike IgG causes acute lung injury by skewing macrophage response towards proinflammatory monocyte/macrophage recruitment and accumulation during acute SARS-CoV-1 infection ${ }^{73}$. These observations are likely linked by antibody-dependent enhancement of coronavirus infection of macrophages ${ }^{58,74}$. In SARS patients, severe SARS was associated with a more robust IgG response ${ }^{75}$; early responders (antibody detectable within 2 weeks) had a higher death rate ${ }^{76,77}$. The pathophysiology of severe and critical SARS and COVID-19 diseases fits a proposed model of antibody-dependent infection of macrophages as the key gate step in disease progression from mild to severe and critical symptoms, and may explain the observed dysregulated immune responses ${ }^{78}$ including apoptosis contributing to development of pan-T cell lymphopenia, proinflammatory cascade with macrophage accumulation, and cytokine and chemokine accumulations in lungs with a cytokine storm in some patients.

\section{Vaccine Risks for Antibody-dependent Enhancement (ADE)}

Many of the viruses associated with ADE have cell membrane fusion mechanisms ${ }^{61}$. For influenza A H1N1, vaccine-induced anti-HA2 antibodies promote virus fusion causing vaccineassociated enhanced respiratory disease (VAERD) ${ }^{79}$. ADE was observed for the respiratory syncytial virus (RSV) in the Bonnet monkey model ${ }^{60}$. Van Erp et al. ${ }^{60}$ recommends avoidance of induction of respiratory syncytial virus (RSV) non-neutralizing antibodies or subneutralizing antibodies to avoid ADE. In a mouse model, attempts to create vaccines for SARS-CoV-1 lead to pulmonary immunopathology upon challenge with SARS-CoV-19; these vaccines included inactivated whole viruses, inactivated viruses with adjuvant, and a recombinant DNA spike (S) protein vaccine in a virus-like particle (VLP)-based vaccine. Enhanced hepatitis was observed in a ferret model with a vaccine with recombinant modified vaccinia virus Ankara (rMVA) expressing the SARS-CoV-1 S protein ${ }^{80}$. Jaume et al. ${ }^{58}$ point out the potential pitfalls associated with immunizations against SARS-CoV-1. This leads to the prediction that new attempts to create either SARS-CoV-1 vaccines ${ }^{81}$, MERS-CoV vaccines ${ }^{11}$, or SARS-CoV-2 vaccines have potentially higher risks for inducing ADE in humans facilitated by antibody infection of phagocytic immune cells. This potential ADE risk is independent of the vaccine technology ${ }^{82}$ or targeting strategy selected due to predicted phagocytic immune cell infections upon antibody uptake. 
Convalescent plasma therapy has been provided to SARS ${ }^{83}$ and COVID-19 ${ }^{84}$ patients. Candidate patients for convalescent plasma therapy are already experiencing advanced clinical disease symptoms, potentially mitigating ADE risk. For Hong Kong SARS patients, convalescent plasma therapy had improved outcomes $(6.4 \%$ mortality rate) when it was provided before day 14 versus after $(21.9 \%$ mortality rate) compared to the overall SARS-related mortality rate in of $17 \%$. This is also being seen for initial COVID-19 patients treated with convalescent plasma therapy ${ }^{84}$.

\section{Antibody Targets}

Analyzing the Cryo-EM structures of MERS-CoV and SARS-CoV-1 spike (S) glycoproteins, Yuan et al. ${ }^{85}$ suggest that the fusion peptide (FP) and the heptad repeat 1 region (HR1) are potential targets for eliciting broadly neutralizing antibodies based on exposure on the surface of the stem region, lack of N-linked glycosylation sites in this region, and sequence conservation. Antibodies that interrupt virus-cell fusion will likely block the infection of immune cells using Fc-mediated uptake of virus ${ }^{58}$. This has been demonstrated for SARS-CoV-1 for antibodies to the HR2 region ${ }^{86-88}$. Likewise, 2019-nCoV antibodies that block cell fusion are predicted to not share the same ADE risk of other 2019-nCoV antibodies. Antibodies that target the $\mathrm{S} \mathrm{RBD}^{89}$ may have an ADE risk unless combined with a second cell fusion blocking antibody.

\section{Targeting Cell Fusion}

In addition to antibodies, peptides targeting HR2 have been shown to effectively block infection in cell and animal models. Multiple peptides based on the heptad repeat regions (HR1 and HR2) have been shown to suppress SARS-CoV-1 cell entry ${ }^{42-46}$. Specific combinations of two peptides show synergistic viral inhibition ${ }^{43}$. An HR2 peptide was effective in a mouse model administered intranasally against human coronavirus $229 \mathrm{E}(\mathrm{HCoV}-229 \mathrm{E})^{48}$. An HR2 peptide combined with human interferon- $\alpha$ (IFN- $\alpha$ ) also have significant synergistic antiviral effect against feline coronavirus $(\mathrm{FCoV})^{90}$. Based on anti-HIV-1 peptide, T-20 ${ }^{91}$, Lambert et al. demonstrate that analogous peptides inhibit respiratory syncytial virus (RSV), human parainfluenza virus type 3 (HPIV-3), and measles virus (MV) ${ }^{92}$. An HR2 peptide can effectively inhibit MERS-CoV replication ${ }^{49}$. Gao et al. ${ }^{41}$ identified an HR2 peptide that inhibits MERS$\mathrm{CoV}$ fusion in their pseudotyped-virus system. MERS-CoV HR1 entry inhibitor peptides have been modified to form intra-molecular salt-bridges and increase peptide solubility ${ }^{50}$. The peptide MERS HP2P-M2 protected C57BL/6 mice and mice deficient for VDJ recombination-activating protein 1 (RAG1); this protection was enhanced by combing this peptide with interferon- $\beta^{50}$. Similar results are demonstrated for additional mouse models ${ }^{93,94}$. Lipopeptides have been design to target cell fusion peptides ${ }^{47}$. An analogous fusion inhibitor, enfuvirtide (T-20), has been approved for treatment of HIV-1 infections ${ }^{91}$. This provides a path forward for peptidebased MCMs for 2019-nCoV. A set of SARS-CoV-1 inhibitory peptides that could be adapted or directly tested on SARS-CoV-2 are illustrated in Figure 3. The SARS-CoV-1 HR2 peptides can be directly tested on 2019-nCoV without modification due to sequence identity in this region of the $\mathrm{S}$ protein.

\section{B cell Vaccine Designs}

B cell vaccines that target the $\mathrm{S}$ protein cell fusion mechanisms have the highest chance of raising neutralizing antibodies with minimal or no ADE risk. Antibodies targeting other portions 
of the S protein or other 2019-nCoV exposed proteins may enable infection of phagocytic immune cells even if they are neutralizing.

\section{T cell Vaccine Designs}

Variation results identified multiple continuous linear segments of critical residues from which $\mathrm{T}$ cell epitopes can be selected in SARS-CoV-2 replicase enzymes and accessory proteins (Figure 2). Antibodies developed against these epitopes are highly unlikely to enable antibody enhanced infection of phagocytic immune cells because they are not exposed on the surface of 2019-nCoV.

\section{Targeting Autophagy}

Coronavirus replication exploits aspects of normal cellular autophagy ${ }^{95}$. SKP2 attenuates autophagy through Beclin1-ubiquination; its inhibition by the licensed drug niclosamide, a treatment for tapeworms, drastically reduced the replications of MERS-CoV in cell culture ${ }^{13}$. Compounds that block autophagy are worth investigating as SARS-CoV-2 MCM.

\section{Targeting Viral Enzymes}

2019-nCoV enzyme proteins are highly conserved with minimal spacer residues (Table 2 and Figure 2). The variation results indicate that available SARS-CoV-1 protein structures (Table 2) can be directly used for in silico docking and high throughput compound screens. SARS-CoV-2 protein structures are becoming rapidly available ${ }^{96}$ for compound screening approaches. The high conservation around enzyme pockets holds promise that compound inhibitors against SARS-CoV-2 will also be effective against SARS-CoV-1 and SARS-like CoV enzymes.

\section{Summary}

Given past data on multiple SARS-CoV-1 and MERS-CoV vaccine efforts which have failed due to ADE in animal models ${ }^{9,11}$, it is reasonable to hypothesize a similar ADE risk for SARS-CoV-2 vaccine efforts unless they specifically target domains which will block virus-immune cell fusion. MCMs based on vaccines, antibodies, or peptides that block cell fusion could minimize predicted ADE risks. Synergy has been observed for combinations of CoV countermeasures including interferon- $\alpha$ and $-\beta$. Small molecules targeting viral enzymes should also be pursued.

\section{Data Availability}

Protein multiple sequence alignments and associated variation files are included in Ricke, Darrell, 2020, "Medical Countermeasures Analysis of 2019-nCoV / SARS-CoV-2 for COVID19", https://doi.org/10.7910/DVN/XWVOA8, Harvard Dataverse, V1.

\section{Acknowledgements}

The author acknowledges Nora Smith for literature search assistance, Irene Stapleford for graphic art assistance, and Dr. Casandra Philipson for proof reading feedback.

\section{Conflicts of Interest}

Dr. Ricke and Dr. Malone have nothing to disclose. 
DISTRIBUTION STATEMENT A. Approved for public release. Distribution is unlimited.

This material is based upon work supported under U.S. Air Force Contract No. FA8702-15-D0001. Any opinions, findings, conclusions or recommendations expressed in this material are those of the author(s) and do not necessarily reflect the views of the Under Secretary of Defense for Research and Engineering.

\section{References}

$1 \quad H u a n g$, C. et al. Clinical features of patients infected with 2019 novel coronavirus in Wuhan, China. Lancet 395, 497-506, doi:https://doi.org/10.1016/S0140-6736(20)30183$\underline{5}$ (2020).

2 Wang, D. et al. Clinical Characteristics of 138 Hospitalized Patients With 2019 Novel Coronavirus-Infected Pneumonia in Wuhan, China. JAMA, doi:10.1001/jama.2020.1585 (2020).

3 Nicholls, J. M. et al. Lung pathology of fatal severe acute respiratory syndrome. Lancet 361, 1773-1778, doi:https://doi.org/10.1016/S0140-6736(03)13413-7 (2003).

4 Zhang, Y. The Epidemiological Characteristics of an Outbreak of 2019 Novel Coronavirus Diseases (COVID-19) - China, 2020, <http://weekly.chinacdc.cn/en/article/id/e53946e2-c6c4-41e9-9a9b-fea8db1a8f51>(

5 Satoh, R. et al. Screening and identification of Thelper 1 and linear immunodominant antibody-binding epitopes in the spike 2 domain and the nucleocapsid protein of feline infectious peritonitis virus. Vaccine 29, 1791-1800, doi:https://doi.org/10.1016/j.vaccine.2010.12.106 (2011).

6 Scott, F. W. Immunization against feline coronaviruses. Adv Exp Med Biol 218, 569-576 (1987).

7 Peiris, J. S. M., Guan, Y. \& Yuen, K. Y. Severe acute respiratory syndrome. Nat Med 10, S88-S97, doi:10.1038/nm1143 (2004).

8 Hui, D. S. C. \& Zumla, A. Severe Acute Respiratory Syndrome: Historical, Epidemiologic, and Clinical Features. Infect Dis Clin North Am 33, 869-889, doi:https://doi.org/10.1016/j.idc.2019.07.001 (2019).

9 Tseng, C.-T. et al. Immunization with SARS coronavirus vaccines leads to pulmonary immunopathology on challenge with the SARS virus. PLoS One 7, e35421, doi:10.1371/journal.pone.0035421 (2012).

10 Wang, S.-F. et al. Antibody-dependent SARS coronavirus infection is mediated by antibodies against spike proteins. Biochem Biophys Res Commun 451, 208-214, doi:https://doi.org/10.1016/j.bbrc.2014.07.090 (2014).

11 Agrawal, A. S. et al. Immunization with inactivated Middle East Respiratory Syndrome coronavirus vaccine leads to lung immunopathology on challenge with live virus. Hum Vaccin Immunother 12, 2351-2356, doi:10.1080/21645515.2016.1177688 (2016).

12 Yang, Y.-p. et al. Application and interpretation of current autophagy inhibitors and activators. Acta Pharmacol Sin 34, 625-635, doi:10.1038/aps.2013.5 (2013).

13 Gassen, N. C. et al. SKP2 attenuates autophagy through Beclin1-ubiquitination and its inhibition reduces MERS-Coronavirus infection. Nat Commun 10, 5770, doi:10.1038/s41467-019-13659-4 (2019). 
14 Chen, Y., Liu, Q. \& Guo, D. Emerging coronaviruses: Genome structure, replication, and pathogenesis. J Med Virol, doi:10.1002/jmv.25681 (2020).

15 Coronavirus COVID-19 Global Cases by Johns Hopkins CSSE, <https://gisanddata.maps.arcgis.com/apps/opsdashboard/index.html\#/bda7594740fd4 0299423467b48e9ecf6> (

16 Yasui, F. et al. Phagocytic cells contribute to the antibody-mediated elimination of pulmonary-infected SARS coronavirus. Virology 454-455, 157-168, doi:https://doi.org/10.1016/j.virol.2014.02.005 (2014).

17 Zhang, Y. Vital Surveillances: The Epidemiological Characteristics of an Outbreak of 2019 Novel Coronavirus Diseases (COVID-19) - China, 2020, <http://weekly.chinacdc.cn/en/article/id/e53946e2-c6c4-41e9-9a9b-fea8db1a8f51>(

18 Chu, H. et al. Middle East Respiratory Syndrome Coronavirus Efficiently Infects Human Primary T Lymphocytes and Activates the Extrinsic and Intrinsic Apoptosis Pathways. J Infect Dis 213, 904-914, doi:10.1093/infdis/jiv380 (2015).

19 Zhou, J., Chu, H., Chan, J. F.-W. \& Yuen, K.-Y. Middle East respiratory syndrome coronavirus infection: virus-host cell interactions and implications on pathogenesis. Virol J 12, 218, doi:10.1186/s12985-015-0446-6 (2015).

20 Huang, K.-J. et al. An interferon- $\gamma$-related cytokine storm in SARS patients. J Med Virol 75, 185-194, doi:10.1002/jmv.20255 (2005).

21 Tisoncik, J. R. et al. Into the eye of the cytokine storm. Microbiol Mol Biol Rev 76, 16-32, doi:10.1128/MMBR.05015-11 (2012).

22 Channappanavar, R. \& Perlman, S. Pathogenic human coronavirus infections: causes and consequences of cytokine storm and immunopathology. Semin Immunopathol 39, 529539, doi:10.1007/s00281-017-0629-x (2017).

23 Wong, R. S. M. et al. Haematological manifestations in patients with severe acute respiratory syndrome: retrospective analysis. BMJ 326, 1358-1362, doi:10.1136/bmj.326.7403.1358 (2003).

$24 \mathrm{Li}, \mathrm{T}$. et al. Significant Changes of Peripheral T Lymphocyte Subsets in Patients with Severe Acute Respiratory Syndrome. J Infect Dis 189, 648-651, doi:10.1086/381535 (2004).

25 Yang, Y. et al. Bcl-xL inhibits T-cell apoptosis induced by expression of SARS coronavirus E protein in the absence of growth factors. Biochem J 392, 135-143, doi:10.1042/BJ20050698 (2005).

26 Li, G. et al. Coronavirus infections and immune responses. J Med Virol, doi:10.1002/jmv.25685 (2020).

27 Gu, J. \& Korteweg, C. Pathology and pathogenesis of severe acute respiratory syndrome. Am J Pathol 170, 1136-1147, doi:10.2353/ajpath.2007.061088 (2007).

$28 \mathrm{Ng}, \mathrm{M}$. H. L. et al. Association of Human-Leukocyte-Antigen Class I (B*0703) and Class II (DRB1*0301) Genotypes with Susceptibility and Resistance to the Development of Severe Acute Respiratory Syndrome. J Infect Dis 190, 515-518, doi:10.1086/421523 (2004).

29 Lin, M. et al. Association of HLA class I with severe acute respiratory syndrome coronavirus infection. BMC Med Genet 4, 9, doi:10.1186/1471-2350-4-9 (2003). 
30 Tang, F. et al. IL-12 RB1 genetic variants contribute to human susceptibility to severe acute respiratory syndrome infection among Chinese. PLoS One 3, e2183, doi:10.1371/journal.pone.0002183 (2008).

31 Ip, W. K. E. et al. Mannose-Binding Lectin in Severe Acute Respiratory Syndrome Coronavirus Infection. J Infect Dis 191, 1697-1704, doi:10.1086/429631 (2005).

32 Menachery, V. D. et al. MERS-CoV and H5N1 influenza virus antagonize antigen presentation by altering the epigenetic landscape. Proc Natl Acad Sci U S A 115, E1012E1021, doi:10.1073/pnas.1706928115 (2018).

33 Wan, Y., Shang, J., Graham, R., Baric, R. S. \& Li, F. Receptor recognition by novel coronavirus from Wuhan: An analysis based on decade-long structural studies of SARS. $J$ Virol, JVI.00127-00120, doi:10.1128/JVI.00127-20 (2020).

34 Zhao, Y. et al. Single-cell RNA expression profiling of ACE2, the putative receptor of Wuhan 2019-nCov. bioRxiv, doi:10.1101/2020.01.26.919985 (2020).

35 Darwin, C. On the Origin of Species. (1859).

36 Kimura, M. Evolutionary Rate at the Molecular Level. Nature 217, 624-626 (1968).

37 Bottema, C. D. K. et al. Missense mutations and evolutionary conservation of amino acids: evidence that many of the amino acids in factor IX function as "spacer" elements. Am J Hum Genet 49, 820-838 (1991).

38 Ricke, D. O. Divergence Model of Protein Evolution. bioRxiv, doi:http://dx.doi.org/10.1101/045930 (2016).

39 Liu, W. J. et al. T-cell immunity of SARS-CoV: Implications for vaccine development against MERS-CoV. Antiviral Res 137, 82-92, doi:https://doi.org/10.1016/j.antiviral.2016.11.006 (2017).

40 Maier, H. J. \& Britton, P. Involvement of autophagy in coronavirus replication. Viruses 4, 3440-3451, doi:10.3390/v4123440 (2012).

41 Gao, J. et al. Structure of the fusion core and inhibition of fusion by a heptad repeat peptide derived from the S protein of Middle East respiratory syndrome coronavirus. J Virol 87, 13134-13140, doi:10.1128/JVI.02433-13 (2013).

42 Yuan, K. et al. Suppression of SARS-CoV entry by peptides corresponding to heptad regions on spike glycoprotein. Biochem Biophys Res Commun 319, 746-752, doi:https://doi.org/10.1016/j.bbrc.2004.05.046 (2004).

43 Liu, I. J. et al. Identification of a minimal peptide derived from heptad repeat (HR) 2 of spike protein of SARS-CoV and combination of HR1-derived peptides as fusion inhibitors. Antiviral Res 81, 82-87, doi:https://doi.org/10.1016/j.antiviral.2008.10.001 (2009).

44 Lai, S.-C. et al. Characterization of neutralizing monoclonal antibodies recognizing a 15residues epitope on the spike protein $\mathrm{HR} 2$ region of severe acute respiratory syndrome coronavirus (SARS-CoV). J Biomed Sci 12, 711-727, doi:10.1007/s11373-005-9004-3 (2005).

45 Bosch, B. J. et al. Severe acute respiratory syndrome coronavirus (SARS-CoV) infection inhibition using spike protein heptad repeat-derived peptides. Proc Natl Acad Sci U S A 101, 8455-8460, doi:10.1073/pnas.0400576101 (2004).

46 Zhu, J. et al. Following the rule: formation of the 6-helix bundle of the fusion core from severe acute respiratory syndrome coronavirus spike protein and identification of 
potent peptide inhibitors. Biochemical and Biophysical Research Communications 319, 283-288, doi:https://doi.org/10.1016/j.bbrc.2004.04.141 (2004).

47 Wang, C. et al. De Novo Design of $\alpha$-Helical Lipopeptides Targeting Viral Fusion Proteins: A Promising Strategy for Relatively Broad-Spectrum Antiviral Drug Discovery. J Med Chem 61, 8734-8745, doi:10.1021/acs.jmedchem.8b00890 (2018).

48 Xia, S. et al. Peptide-Based Membrane Fusion Inhibitors Targeting HCoV-229E Spike Protein HR1 and HR2 Domains. Int J Mol Sci 19, 487, doi:10.3390/ijms19020487 (2018).

49 Lu, L. et al. Structure-based discovery of Middle East respiratory syndrome coronavirus fusion inhibitor. Nat Commun 5, 3067, doi:10.1038/ncomms4067 (2014).

50 Xia, S. et al. Middle East respiratory syndrome coronavirus (MERS-CoV) entry inhibitors targeting spike protein. Virus Res 194, 200-210, doi:https://doi.org/10.1016/j.virusres.2014.10.007 (2014).

51 Ricke, D. O. \& Shcherbina, A. Dawn: Rapid large-scale protein multiple sequence alignment and conservation analysis. 2015 IEEE High Performance Extreme Computing Conference (HPEC), doi:10.1109/HPEC.2015.7322463 (2015).

52 Waterhouse, A. M., Procter, J. B., Martin, D. M. A., Clamp, M. \& Barton, G. J. Jalview Version 2-a multiple sequence alignment editor and analysis workbench.

Bioinformatics 25, 1189-1191, doi:10.1093/bioinformatics/btp033 (2009).

53 Berman, H. M. et al. The Protein Data Bank. Nucleic Acids Res 28, 235-242 (2000).

54 Jmol: an open-source Java viewer for chemical structures in $3 D,<w w w . j m o l . o r g>$ (

55 Pyrc, K., Berkhout, B. \& Hoek, L. v. d. Antiviral Strategies Against Human Coronaviruses. Infect Disorders - Drug Targets 7, 59-66, doi:http://dx.doi.org/10.2174/187152607780090757 (2007).

$56 \mathrm{Xu}, \mathrm{X}$. et al. Evolution of the novel coronavirus from the ongoing Wuhan outbreak and modeling of its spike protein for risk of human transmission. Sci China Life Sci, doi:10.1007/s11427-020-1637-5 (2020).

57 Letko, M. \& Munster, V. Functional assessment of cell entry and receptor usage for lineage B $\beta$-coronaviruses, including 2019-nCoV. bioRxiv, 2020.2001.2022.915660, doi:10.1101/2020.01.22.915660 (2020).

58 Jaume, M. et al. Anti-severe acute respiratory syndrome coronavirus spike antibodies trigger infection of human immune cells via a $\mathrm{pH}$ - and cysteine protease-independent FcyR pathway. J Virol 85, 10582-10597, doi:10.1128/JVI.00671-11 (2011).

59 Wang, F. S. et al. Acquired but reversible loss of erythrocyte complement receptor 1 (CR1, CD35) and its longitudinal alteration in patients with severe acute respiratory syndrome. Clin Exp Immunol 139, 112-119, doi:10.1111/j.1365-2249.2005.02681.x (2005).

60 van Erp, E. A. et al. In Vitro Enhancement of Respiratory Syncytial Virus Infection by Maternal Antibodies Does Not Explain Disease Severity in Infants. J Virol 91, e0085100817, doi:10.1128/JVI.00851-17 (2017).

61 Smatti, M. K., Al Thani, A. A. \& Yassine, H. M. Viral-Induced Enhanced Disease Illness. Front Microbiol 9, 2991, doi:10.3389/fmicb.2018.02991 (2018).

62 Jares Baglivo, S. \& Polack, F. P. The long road to protect infants against severe RSV lower respiratory tract illness. F1000Res 8, F1000 Faculty Rev-1610, doi:10.12688/f1000research.18749.1 (2019). 
63 Winarski, K. L. et al. Antibody-dependent enhancement of influenza disease promoted by increase in hemagglutinin stem flexibility and virus fusion kinetics. Proc Natl Acad Sci 116, 15194, doi:10.1073/pnas.1821317116 (2019).

64 Panesar, N. S. Lymphopenia in SARS. Lancet 361, 1985, doi:10.1016/S01406736(03)13557-X (2003).

$65 \mathrm{Xu}, \mathrm{Z}$. et al. Pathological findings of COVID-19 associated with acute respiratory distress syndrome. Lancet Respir Med, doi:10.1016/S2213-2600(20)30076-X.

66 Guan, W.-j. et al. Clinical characteristics of 2019 novel coronavirus infection in China. medRxiv, 2020.2002.2006.20020974, doi:10.1101/2020.02.06.20020974 (2020).

$67 \mathrm{Li}, \mathrm{W}$. et al. Angiotensin-converting enzyme 2 is a functional receptor for the SARS coronavirus. Nature 426, 450-454, doi:10.1038/nature02145 (2003).

68 Jeffers, S. A. et al. CD209L (L-SIGN) is a receptor for severe acute respiratory syndrome coronavirus. Proc Natl Acad Sci U S A 101, 15748, doi:10.1073/pnas.0403812101 (2004).

69 Liu, H., Yu, W., Liou, L.-Y. \& Rice, A. P. Isolation and characterization of the human DCSIGN and DC-SIGNR promoters. Gene 313, 149-159, doi:https://doi.org/10.1016/S03781119(03)00674-7 (2003).

70 Chan, V. S. F. et al. Homozygous L-SIGN (CLEC4M) plays a protective role in SARS coronavirus infection. Nat Genet 38, 38-46, doi:10.1038/ng1698 (2006).

71 Chen, J. et al. Cellular Immune Responses to Severe Acute Respiratory Syndrome Coronavirus (SARS-CoV) Infection in Senescent BALB/c Mice: CD4+ T Cells Are Important in Control of SARS-CoV Infection. J Virol 84, 1289, doi:10.1128/JVI.01281-09 (2010).

72 Zhao, J., Zhao, J., Van Rooijen, N. \& Perlman, S. Evasion by stealth: inefficient immune activation underlies poor $\mathrm{T}$ cell response and severe disease in SARS-CoV-infected mice. PLoS Pathog 5, e1000636, doi:10.1371/journal.ppat.1000636 (2009).

73 Liu, L. et al. Anti-spike IgG causes severe acute lung injury by skewing macrophage responses during acute SARS-CoV infection. JCI Insight 4, e123158, doi:10.1172/jci.insight.123158 (2019).

74 Dandekar, A. A. \& Perlman, S. Immunopathogenesis of coronavirus infections: implications for SARS. Nat Rev Immunol 5, 917-927, doi:10.1038/nri1732 (2005).

75 Lee, N. et al. Anti-SARS-CoV IgG response in relation to disease severity of severe acute respiratory syndrome. J Clin Virol 35, 179-184, doi:https://doi.org/10.1016/j.jcv.2005.07.005 (2006).

76 Ho, M.-S. et al. Neutralizing Antibody Response and SARS Severity. Emerg Infect Dis, doi:https://dx.doi.org/10.3201/eid1111.040659 (2005).

77 Zhang, L. et al. Antibody responses against SARS coronavirus are correlated with disease outcome of infected individuals. J Med Virol 78, 1-8, doi:10.1002/jmv.20499 (2006).

78 Channappanavar, R. et al. Dysregulated Type I Interferon and Inflammatory MonocyteMacrophage Responses Cause Lethal Pneumonia in SARS-CoV-Infected Mice. Cell Host Microbe 19, 181-193, doi:10.1016/j.chom.2016.01.007 (2016).

79 Khurana, S. et al. Vaccine-Induced Anti-HA2 Antibodies Promote Virus Fusion and Enhance Influenza Virus Respiratory Disease. Sci Transl Med 5, 200ra114, doi:10.1126/scitranslmed.3006366 (2013).

80 Weingartl, H. et al. Immunization with Modified Vaccinia Virus Ankara-Based Recombinant Vaccine against Severe Acute Respiratory Syndrome Is Associated with 
Enhanced Hepatitis in Ferrets. J Virol 78, 12672, doi:10.1128/JVI.78.22.1267212676.2004 (2004).

81 Severe Acute Respiratory Syndrome (SARS) Vaccine, $<$ https://www.bcm.edu/departments/pediatrics/sections-divisions-centers/tropicalmedicine/research/vaccine-development/sarsvaccine> (2020).

82 Rauch, S., Jasny, E., Schmidt, K. E. \& Petsch, B. New Vaccine Technologies to Combat Outbreak Situations. Front Immunol 9, 1963, doi:10.3389/fimmu.2018.01963 (2018).

83 Cheng, Y. et al. Use of convalescent plasma therapy in SARS patients in Hong Kong. Eur J Clin Microbiol Infect Dis 24, 44-46, doi:10.1007/s10096-004-1271-9 (2005).

84 Ravindranath, P. Convalescent plasma therapy tested on critically ill COVID-19 patients, <https://journosdiary.com/2020/02/15/convalescent-plasma-therapy-covid-19/>1

85 Yuan, Y. et al. Cryo-EM structures of MERS-CoV and SARS-CoV spike glycoproteins reveal the dynamic receptor binding domains. Nat Commun 8, 15092, doi:10.1038/ncomms15092 (2017).

86 Lip, K.-M. et al. Monoclonal Antibodies Targeting the HR2 Domain and the Region Immediately Upstream of the HR2 of the S Protein Neutralize In Vitro Infection of Severe Acute Respiratory Syndrome Coronavirus. J Virol 80, 941, doi:10.1128/JVI.80.2.941950.2006 (2006).

87 Tripet, B., Kao, D. J., Jeffers, S. A., Holmes, K. V. \& Hodges, R. S. Template-based coiledcoil antigens elicit neutralizing antibodies to the SARS-coronavirus. J Struct Biol 155, 176194, doi:https://doi.org/10.1016/j.jsb.2006.03.019 (2006).

88 Keng, E. C. T. et al. Amino Acids 1055 to 1192 in the S2 Region of Severe Acute Respiratory Syndrome Coronavirus S Protein Induce Neutralizing Antibodies: Implications for the Development of Vaccines and Antiviral Agents. J Virol 79, 32893296, doi:10.1128/JVI.79.6.3289-3296.2005 (2005).

89 Tian, X. et al. Potent binding of 2019 novel coronavirus spike protein by a SARS coronavirus-specific human monoclonal antibody. Emerg Microbes Infect 9, 382-385, doi:10.1080/22221751.2020.1729069 (2020).

90 Liu, I. J., Tsai, W.-T., Hsieh, L.-E. \& Chueh, L.-L. Peptides corresponding to the predicted heptad repeat 2 domain of the feline coronavirus spike protein are potent inhibitors of viral infection. PLoS One 8, e82081, doi:10.1371/journal.pone.0082081 (2013).

91 Kilby, J. M. et al. Potent suppression of HIV-1 replication in humans by T-20, a peptide inhibitor of gp41-mediated virus entry. Nat Med 4, 1302-1307, doi:10.1038/3293 (1998).

92 Lambert, D. M. et al. Peptides from conserved regions of paramyxovirus fusion (F) proteins are potent inhibitors of viral fusion. Proc Natl Acad Sci 93, 2186, doi:10.1073/pnas.93.5.2186 (1996).

93 Channappanavar, R. et al. Protective Effect of Intranasal Regimens Containing Peptidic Middle East Respiratory Syndrome Coronavirus Fusion Inhibitor Against MERS-CoV Infection. J Infect Dis 212, 1894-1903, doi:10.1093/infdis/jiv325 (2015).

94 Jiang, S. et al. Intranasally administered peptidic viral fusion inhibitor protected hDPP4 transgenic mice from MERS-CoV infection. Lancet 386, S44, doi:10.1016/S01406736(15)00625-X (2015). 
95 Prentice, E., Jerome, W. G., Yoshimori, T., Mizushima, N. \& Denison, M. R. Coronavirus Replication Complex Formation Utilizes Components of Cellular Autophagy. J Biol Chem 279, 10136-10141 (2004).

96 Liu, X., Zhang, B., Jin, Z., Yang, H. \& Rao, Z. The crystal structure of COVID-19 main protease in complex with an inhibitor N3, <http://www.rcsb.org/structure/6LU7> (2020).

97 Narayanan, K. et al. Severe Acute Respiratory Syndrome Coronavirus nsp1 Suppresses Host Gene Expression, Including That of Type I Interferon, in Infected Cells. J Viro/ 82, 4471, doi:10.1128/JVI.02472-07 (2008).

98 Narayanan, K. et al. Severe acute respiratory syndrome coronavirus nsp1 suppresses host gene expression, including that of type I interferon, in infected cells. J Virol 82, 4471-4479, doi:10.1128/JVI.02472-07 (2008).

99 Serrano, P. et al. Nuclear Magnetic Resonance Structure of the N-Terminal Domain of Nonstructural Protein 3 from the Severe Acute Respiratory Syndrome Coronavirus. J Virol 81, 12049, doi:10.1128/JVI.00969-07 (2007).

100 Saikatendu, K. S. et al. Structural Basis of Severe Acute Respiratory Syndrome Coronavirus ADP-Ribose-1"-Phosphate Dephosphorylation by a Conserved Domain of nsP3. Structure 13, 1665-1675, doi:https://doi.org/10.1016/j.str.2005.07.022 (2005).

101 Ratia, K. et al. Severe acute respiratory syndrome coronavirus papain-like protease: structure of a viral deubiquitinating enzyme. Proc Natl Acad Sci U S A 103, 5717-5722, doi:10.1073/pnas.0510851103 (2006).

102 Beachboard, D. C., Anderson-Daniels, J. M. \& Denison, M. R. Mutations across murine hepatitis virus nsp4 alter virus fitness and membrane modifications. J Virol 89, 20802089, doi:10.1128/JVI.02776-14 (2015).

103 Yang, H. et al. The crystal structures of severe acute respiratory syndrome virus main protease and its complex with an inhibitor. Proc Natl Acad Sci 100, 13190, doi:10.1073/pnas.1835675100 (2003).

104 Angelini, M. M., Akhlaghpour, M., Neuman, B. W. \& Buchmeier, M. J. Severe acute respiratory syndrome coronavirus nonstructural proteins 3,4 , and 6 induce doublemembrane vesicles. mBio 4, e00524-00513, doi:10.1128/mBio.00524-13 (2013).

105 Cottam, E. M., Whelband, M. C. \& Wileman, T. Coronavirus NSP6 restricts autophagosome expansion. Autophagy 10, 1426-1441, doi:10.4161/auto.29309 (2014).

106 Kirchdoerfer, R. N. \& Ward, A. B. Structure of the SARS-CoV nsp12 polymerase bound to nsp7 and nsp8 co-factors. Nat Commun 10, 2342, doi:10.1038/s41467-019-10280-3 (2019).

107 Zhai, Y. et al. Insights into SARS-CoV transcription and replication from the structure of the nsp7-nsp8 hexadecamer. Nat Struct Mol Biol 12, 980-986, doi:10.1038/nsmb999 (2005).

108 Sutton, G. et al. The nsp9 Replicase Protein of SARS-Coronavirus, Structure and Functional Insights. Structure 12, 341-353, doi:https://doi.org/10.1016/j.str.2004.01.016 (2004).

109 Ma, Y. et al. Structural basis and functional analysis of the SARS coronavirus nsp14nsp10 complex. Proc Natl Acad Sci U S A 112, 9436-9441, doi:10.1073/pnas.1508686112 (2015). 
110 Decroly, E. et al. Crystal Structure and Functional Analysis of the SARS-Coronavirus RNA Cap 2'-O-Methyltransferase nsp10/nsp16 Complex. PLoS Pathog 7, e1002059, doi:10.1371/journal.ppat.1002059 (2011).

111 Jia, Z. et al. Delicate structural coordination of the Severe Acute Respiratory Syndrome coronavirus Nsp13 upon ATP hydrolysis. Nucleic Acids Res 47, 6538-6550, doi:10.1093/nar/gkz409 (2019).

112 Surya, W., Li, Y. \& Torres, J. Structural model of the SARS coronavirus E channel in LMPG micelles. Biochim Biophys Acta Biomembranes 1860, 1309-1317, doi:https://doi.org/10.1016/j.bbamem.2018.02.017 (2018).

113 Shi, P. et al. PEDV nsp16 negatively regulates innate immunity to promote viral proliferation. Virus Res 265, 57-66, doi:https://doi.org/10.1016/j.virusres.2019.03.005 (2019).

114 Wilson, L., Gage, P. \& Ewart, G. Hexamethylene amiloride blocks E protein ion channels and inhibits coronavirus replication. Virology 353, 294-306, doi:https://doi.org/10.1016/j.virol.2006.05.028 (2006).

115 Li, Y., Surya, W., Claudine, S. \& Torres, J. Structure of a conserved Golgi complextargeting signal in coronavirus envelope proteins. J Biol Chem 289, 12535-12549, doi:10.1074/jbc.M114.560094 (2014).

116 Schoeman, D. \& Fielding, B. C. Coronavirus envelope protein: current knowledge. Virol J 16, 69, doi:10.1186/s12985-019-1182-0 (2019).

117 Nieto-Torres, J. L. et al. Severe acute respiratory syndrome coronavirus envelope protein ion channel activity promotes virus fitness and pathogenesis. PLoS Pathog 10, e1004077, doi:10.1371/journal.ppat.1004077 (2014).

118 Nieto-Torres, J. L. et al. Severe acute respiratory syndrome coronavirus E protein transports calcium ions and activates the NLRP3 inflammasome. Virology 485, 330-339, doi:10.1016/j.virol.2015.08.010 (2015).

119 Jimenez-Guardeño, J. M. et al. The PDZ-Binding Motif of Severe Acute Respiratory Syndrome Coronavirus Envelope Protein Is a Determinant of Viral Pathogenesis. PLoS Pathog 10, e1004320, doi:10.1371/journal.ppat.1004320 (2014).

120 Jimenez-Guardeño, J. M. et al. Identification of the Mechanisms Causing Reversion to Virulence in an Attenuated SARS-CoV for the Design of a Genetically Stable Vaccine. PLoS Pathog 11, e1005215, doi:10.1371/journal.ppat.1005215 (2015).

121 Tseng, Y.-T., Chang, C.-H., Wang, S.-M., Huang, K.-J. \& Wang, C.-T. Identifying SARS-CoV Membrane Protein Amino Acid Residues Linked to Virus-Like Particle Assembly. PLoS One 8, e64013, doi:10.1371/journal.pone.0064013 (2013).

122 Chen, C.-Y. et al. Structure of the SARS Coronavirus Nucleocapsid Protein RNA-binding Dimerization Domain Suggests a Mechanism for Helical Packaging of Viral RNA. J Mol Biol 368, 1075-1086, doi:https://doi.org/10.1016/j.jmb.2007.02.069 (2007).

123 Nelson, C. A., Pekosz, A., Lee, C. A., Diamond, M. S. \& Fremont, D. H. Structure and Intracellular Targeting of the SARS-Coronavirus Orf7a Accessory Protein. Structure 13, 75-85, doi:https://doi.org/10.1016/j.str.2004.10.010 (2005).

124 Hänel, K., Stangler, T., Stoldt, M. \& Willbold, D. Solution structure of the X4 protein coded by the SARS related coronavirus reveals an immunoglobulin like fold and suggests 
a binding activity to integrin I domains. J Biomed Sci 13, 281-293, doi:10.1007/s11373005-9043-9 (2006).

125 Fielding, B. C. et al. Characterization of a unique group-specific protein (U122) of the severe acute respiratory syndrome coronavirus. J Virol 78, 7311-7318, doi:10.1128/JVI.78.14.7311-7318.2004 (2004).

126 Arnaout, M. A. Leukocyte Adhesion Molecules Deficiency: Its Structural Basis, Pathophysiology and Implications for Modulating the Inflammatory Response. Immunol Rev 114, 145-180, doi:10.1111/j.1600-065X.1990.tb00564.x (1990).

127 Teoh, K.-T. et al. The SARS coronavirus E protein interacts with PALS1 and alters tight junction formation and epithelial morphogenesis. Mol Biol Cell 21, 3838-3852, doi:10.1091/mbc.E10-04-0338 (2010).

128 Almeida, M. S., Johnson, M. A., Herrmann, T., Geralt, M. \& Wüthrich, K. Novel $\beta$-Barrel Fold in the Nuclear Magnetic Resonance Structure of the Replicase Nonstructural Protein 1 from the Severe Acute Respiratory Syndrome Coronavirus. J Virol 81, 3151, doi:10.1128/JVI.01939-06 (2007).

129 Lin, M.-H. et al. Disulfiram can inhibit MERS and SARS coronavirus papain-like proteases via different modes. Antiviral Res 150, 155-163, doi:https://doi.org/10.1016/j.antiviral.2017.12.015 (2018).

130 Chen, Y. et al. Biochemical and Structural Insights into the Mechanisms of SARS Coronavirus RNA Ribose 2'-O-Methylation by nsp16/nsp10 Protein Complex. PLoS Pathog 7, e1002294, doi:10.1371/journal.ppat.1002294 (2011).

131 Ma, Y. et al. Structural basis and functional analysis of the SARS coronavirus nsp14nsp10 complex. Proc Nat Acad Sci U S A 112, 9436, doi:10.1073/pnas.1508686112 (2015).

$132 \mathrm{Xu}, \mathrm{X}$. et al. New Antiviral Target Revealed by the Hexameric Structure of Mouse Hepatitis Virus Nonstructural Protein nsp15. J Virol 80, 7909, doi:10.1128/JVI.00525-06 (2006).

133 Saikatendu, K. S. et al. Ribonucleocapsid Formation of Severe Acute Respiratory Syndrome Coronavirus through Molecular Action of the N-Terminal Domain of $\mathrm{N}$ Protein. J Virol 81, 3913, doi:10.1128/JVI.02236-06 (2007).

134 Xue, X. et al. Regulator-dependent mechanisms of C3b processing by factor I allow differentiation of immune responses. Nat Struct Mol Biol 24, 643-651, doi:10.1038/nsmb.3427 (2017).

135 Wrapp, D. et al. Cryo-EM structure of the 2019-nCoV spike in the prefusion conformation. Science, eabb2507, doi:10.1126/science.abb2507 (2020).

136 Sainz, B., Jr. et al. Inhibition of severe acute respiratory syndrome-associated coronavirus (SARS-CoV) infectivity by peptides analogous to the viral spike protein. Virus Res 120, 146-155, doi:10.1016/j.virusres.2006.03.001 (2006).

137 Liu, S. et al. Interaction between heptad repeat 1 and 2 regions in spike protein of SARSassociated coronavirus: implications for virus fusogenic mechanism and identification of fusion inhibitors. Lancet 363, 938-947, doi:https://doi.org/10.1016/S01406736(04)15788-7 (2004). 
138 Ujike, M. et al. Heptad Repeat-Derived Peptides Block Protease-Mediated Direct Entry from the Cell Surface of Severe Acute Respiratory Syndrome Coronavirus but Not Entry via the Endosomal Pathway. J Virol 82, 588, doi:10.1128/JVI.01697-07 (2008). 
Tables

Table 1. 2019-nCoV proteins**

\begin{tabular}{|c|c|c|c|}
\hline Protein & Function & Cofactors & References \\
\hline nsp1 & $\begin{array}{l}\text { cellular mRNA degradation, inhibiting type I } \\
\text { interferon (IFN) expression }\end{array}$ & & 97,98 \\
\hline nsp2 & unknown & & \\
\hline nsp3 & multidomain protein & & \\
\hline nsp3a & interacts with single-stranded RNA & & 99 \\
\hline nsp3b & ADP-ribose 1"-phosphatase & & 100 \\
\hline nsp3d & $\begin{array}{l}\text { papain-like protease (Plpro), deubiquitinating } \\
\text { enzyme (DUB) }\end{array}$ & & 101 \\
\hline nsp4 & double-membrane vesicles (DMV) formation & & 102 \\
\hline nsp5 & 3C-like protease (3CLpro) & & 103 \\
\hline nsp6 & $\begin{array}{l}\text { restricting autophagosome expansion, DMV } \\
\text { formation }\end{array}$ & & 104,105 \\
\hline nsp7 & RNA binding & nsp8:nsp12 & 106,107 \\
\hline nsp8 & RNA binding; primase & nsp7:nsp12, nsp9 & 106,107 \\
\hline nsp9 & RNA binding, dimerization & nsp8 & 108 \\
\hline nsp10 & scaffold cofactor & nsp10, nsp16 & 109,110 \\
\hline nsp11 & unknown & & \\
\hline nsp12 & RNA-dependent RNA polymerase (RdRp) & nsp7:nsp8, nsp14 & 106 \\
\hline nsp13 & RNA helicase, 5' triphosphatase & & 111 \\
\hline nsp14 & $\begin{array}{l}\text { 3'-5' exoribonuclease (ExoN), guanine-N7 } \\
\text { methyl transferase (N7-Mtase) for mRNA } \\
\text { capping, nsp12:nsp14 RNA synthesis and } \\
\text { proofreading }\end{array}$ & & 109 \\
\hline nsp15 & endoribonuclease & & 112 \\
\hline nsp16 & $\begin{array}{l}\text { nsp16:nsp10 RNA cap 2'-O-methyltransferase, } \\
\text { negatively regulates innate immunity }\end{array}$ & & 110,113 \\
\hline $\mathrm{E}$ & $\begin{array}{l}\text { forms homopentameric ion channels (IC) with } \\
\text { poor ion selectivity, Golgi complex-targeting } \\
\text { signal, PDZ-binding motif (PBM) }\end{array}$ & & $114-120$ \\
\hline $\mathrm{M}$ & membrane protein & & 121 \\
\hline $\mathrm{N}$ & packages viral RNA & & 122 \\
\hline \multicolumn{4}{|l|}{ ORF3a } \\
\hline \multicolumn{4}{|l|}{ ORF6 } \\
\hline ORF7a & Ig-like domain, ER retention signal & & $123-126$ \\
\hline \multicolumn{4}{|l|}{ ORF7b } \\
\hline \multicolumn{4}{|l|}{ ORF8 } \\
\hline ORF10 & unknown & & \\
\hline $\mathrm{S}$ & receptor binding, cell fusion & & 85 \\
\hline
\end{tabular}


*The E protein IC releases calcium from the endoplasmic reticulum intermediate compartment (ERGIC), leading to NLRP3 inflammasome activation ${ }^{117,118}$. The E protein has a PDZ-binding motif $(\mathrm{PBM})^{116}$ that interacts with syntenin PDZ motifs to activate $\mathrm{p} 38$ mitogen-activated protein kinase (MAPK) pathway and promotes an acute proinflammatory response ${ }^{119}$ and a virus PBM domain is required for virulence ${ }^{120}$. The E protein PDZ-binding motif binds to PALS1 and alters tight junction formation and epithelial morphogenesis ${ }^{127}$. The envelope (E) protein includes two pathways to promote inflammation; these may contribute to the ADE response. ORF7a protein has Ig-like domain ${ }^{123}$. Hänel et al. ${ }^{124}$ suggest that this ORF7a possess binding activity for $\alpha_{\mathrm{L}}$ integrin I domain of LFA-1 suggesting that this might block newly synthesized LFA-1 molecules from reaching the cell surface because ORF7a contains an ER retention signal ${ }^{125}$. Loss of LFA-1 negatively impacts immune responses ${ }^{126}$. This suggests possible interference of ORF7a with immune surveillance mechanisms. 
Table 2. 2019-nCoV Variance Analysis

\begin{tabular}{|c|c|c|c|c|c|c|c|c|}
\hline Protein & V1: Critical & V2 & V3 & V4 & V5+: Spacers & Residues & Fraction & Structure \\
\hline nsp1 & 112 & 40 & 19 & 3 & 7 & 181 & 0.84 & 2GDT:A $A^{128}$ \\
\hline nsp2 & 279 & 187 & 101 & 46 & 25 & 638 & 0.73 & \\
\hline nsp3 & 996 & 514 & 239 & 115 & 92 & 1,956 & 0.77 & $2 G R I: A^{99}$ \\
\hline nsp3a & 82 & 35 & 20 & 22 & 12 & 171 & 0.68 & $2 A C F: A^{100}$ \\
\hline $\mathrm{Pl}_{\text {pro }}$ & 212 & 68 & 24 & 10 & 5 & 319 & 0.88 & 5Y3E: $\mathrm{A}^{129}$ \\
\hline nsp4 & 337 & 112 & 34 & 13 & 4 & 500 & 0.90 & \\
\hline nsp5 & 254 & 46 & 4 & 2 & 0 & 306 & 0.98 & 6 LU7 $^{96}$ \\
\hline nsp6 & 209 & 64 & 15 & 2 & 0 & 290 & 0.94 & \\
\hline nsp7 & 69 & 13 & 1 & 0 & 0 & 83 & 0.99 & $\begin{array}{l}2 \mathrm{AHM}: \mathrm{A}^{10} \\
7\end{array}$ \\
\hline nsp8 & 170 & 26 & 2 & 0 & 0 & 198 & 0.99 & $\begin{array}{l}2 \mathrm{AHM}: \mathrm{G}^{10} \\
7\end{array}$ \\
\hline nsp9 & 95 & 16 & 2 & 0 & 0 & 113 & 0.98 & $\begin{array}{l}1 U W 7: A^{10} \\
8\end{array}$ \\
\hline nsp10 & 109 & 27 & 3 & 0 & 0 & 139 & 0.98 & $3 R 24: B^{130}$ \\
\hline nsp12 & 5,226 & 1374 & 346 & 105 & 50 & 7,101 & 0.93 & \\
\hline nsp13 & 538 & 61 & 2 & 1 & 0 & 602 & 1.00 & 6JYT: $A^{111}$ \\
\hline nsp14 & 442 & 78 & 7 & 0 & 0 & 527 & 0.99 & $5 C 8 T: B^{131}$ \\
\hline nsp15 & 246 & 76 & 17 & 6 & 1 & 346 & 0.93 & 2GTH:A ${ }^{132}$ \\
\hline nsp16 & 230 & 55 & 8 & 1 & 2 & 296 & 0.96 & $3 R 24: A^{130}$ \\
\hline$E$ & 24 & 33 & 17 & 5 & 3 & 82 & 0.70 & $5 \times 29: A^{112}$ \\
\hline$M$ & 178 & 29 & 11 & 4 & 0 & 222 & 0.93 & \\
\hline $\mathrm{N}$ & 294 & 76 & 33 & 15 & 4 & 422 & 0.88 & 2OFZ:A ${ }^{133}$ \\
\hline ORF3a & 107 & 79 & 54 & 20 & 15 & 275 & 0.68 & \\
\hline ORF6 & 17 & 21 & 22 & 3 & 0 & 63 & 0.60 & \\
\hline ORF7a & 55 & 28 & 30 & 10 & 4 & 127 & 0.65 & 1XAK:A ${ }^{123}$ \\
\hline ORF7b & 5 & 33 & 11 & 4 & 1 & 54 & 0.70 & \\
\hline ORF8 & 59 & 39 & 15 & 8 & 0 & 121 & 0.81 & 5032:1134 \\
\hline ORF10 & 38 & 0 & 0 & 0 & 0 & 38 & 1.00 & \\
\hline$S$ & 650 & 263 & 123 & 107 & 152 & 1,295 & 0.71 & 6CRZ:A ${ }^{135}$ \\
\hline
\end{tabular}

\section{Figures}

Figure 1. Disease progression model with normal immune responses during the initial mild symptoms phase (see 1-3). Antigen presenting cells migrate to the lymph nodes to activate Tcells (2a). The progression gate to severe and critical disease is the infection of phagocytic immune cells (3a) leading to immune dysregulation (4b). In the lungs, chemokines attract additional dendritic cells and immature macrophages that are subsequently infected in an positive feedback-loop infection cascade (4b). Virus and infected phagocytic immune cells disseminate throughout the body infecting additional organs ( $5 \& 6)$. Levels of chemokine and cytokines in the lungs from infected cells can create a cytokine storm (6). 


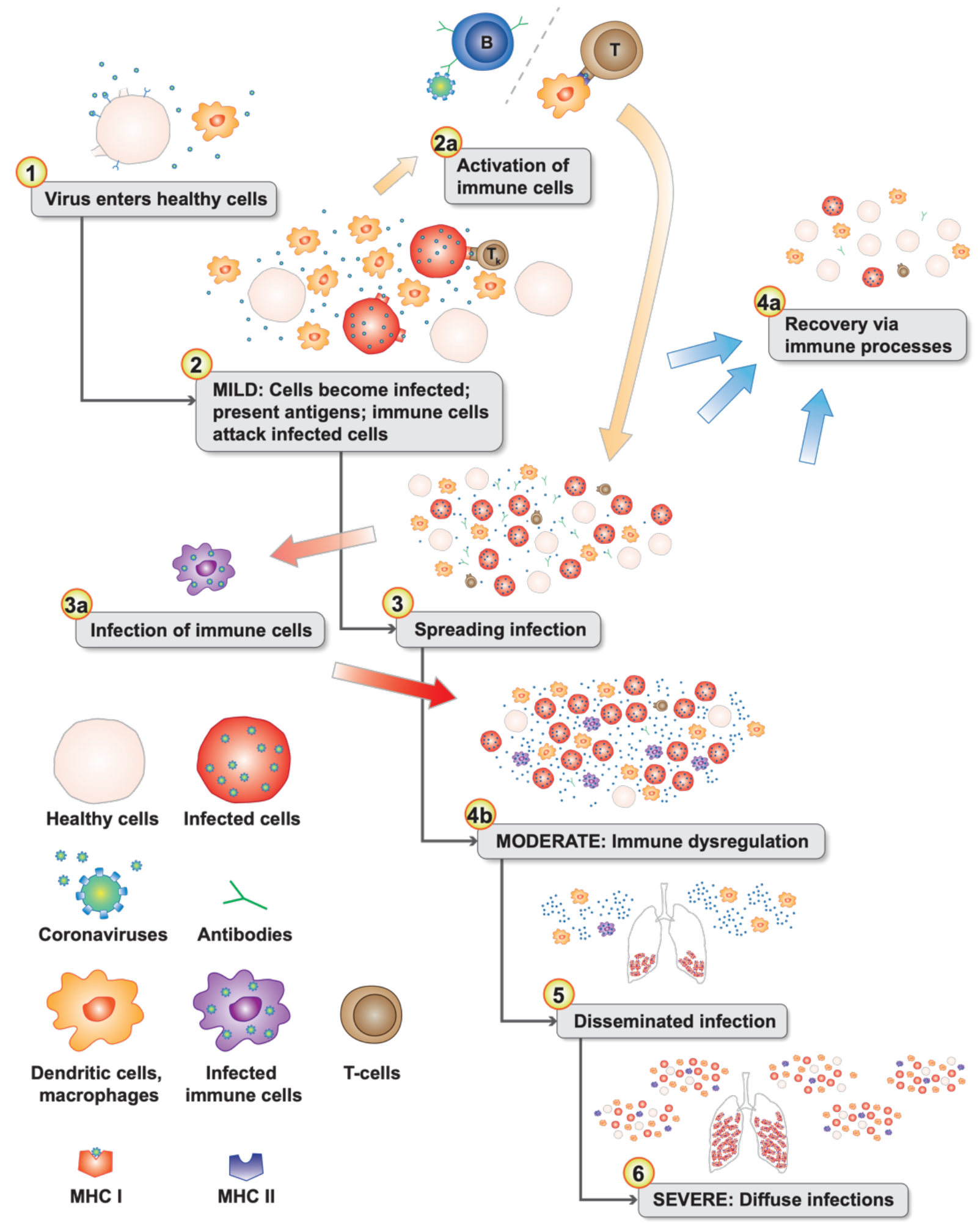

Figure 2. 2019-nCoV variation results. Amino acid residue color code: dark green (critical residues), light green (critical residues with conservative substitutions or variant in less than 10 
sequences, yellow (3 variants), light blue (4 variants; likely spacer residues), and blue (5+ variants; spacer residues). 
nsp1

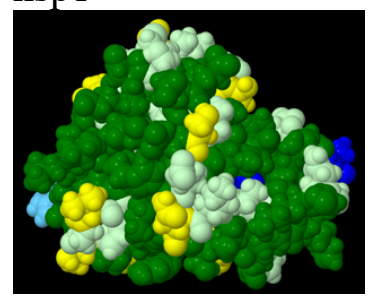

nsp3

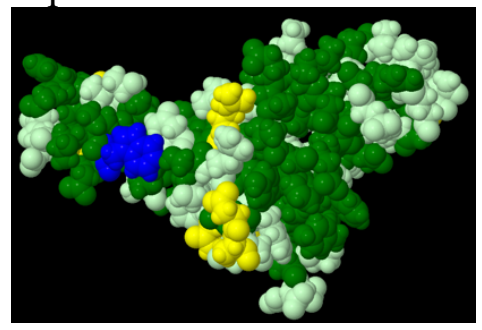

nsp3a

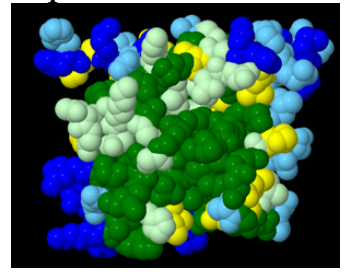

PL-pro protease

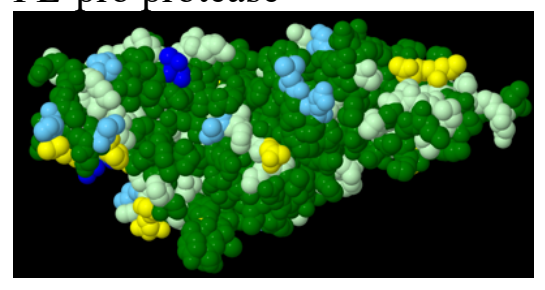

nsp5-3CL protease

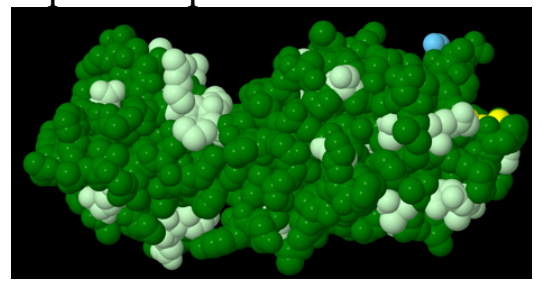

nsp7 \& nsp8

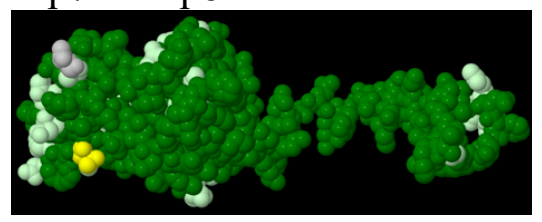

nsp9

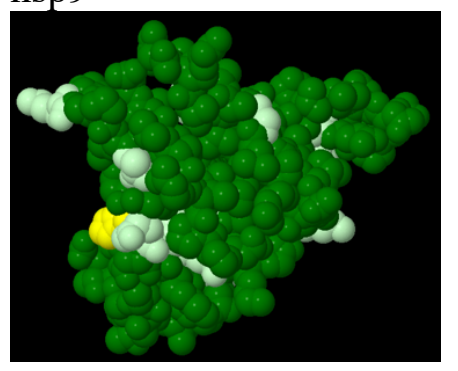

nsp 10

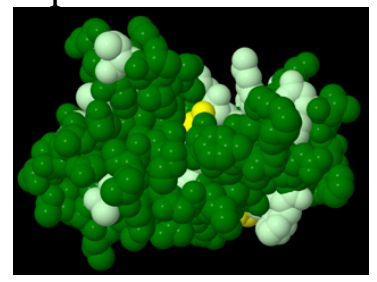

nsp13

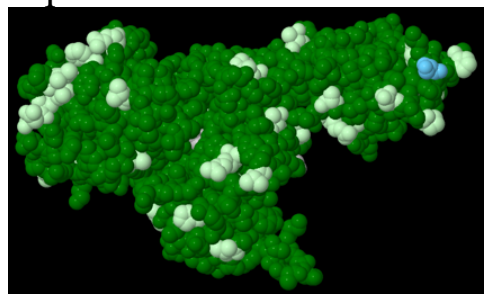

nsp14

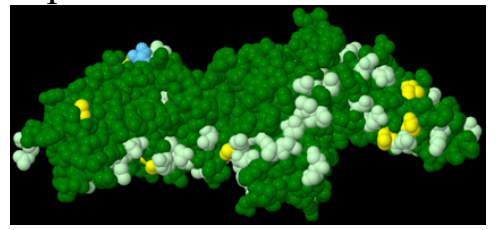

nsp 15

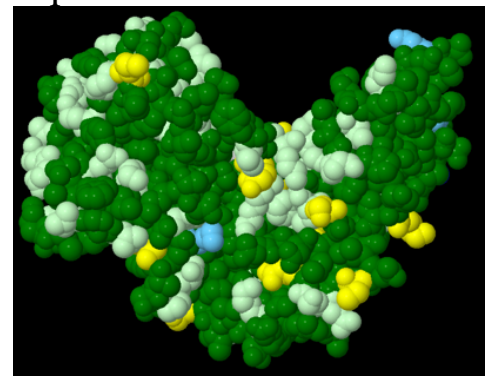

nsp16

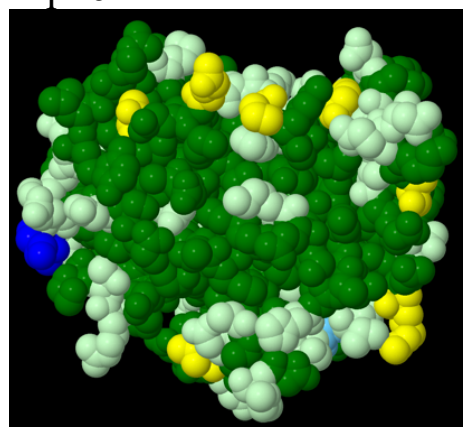

S

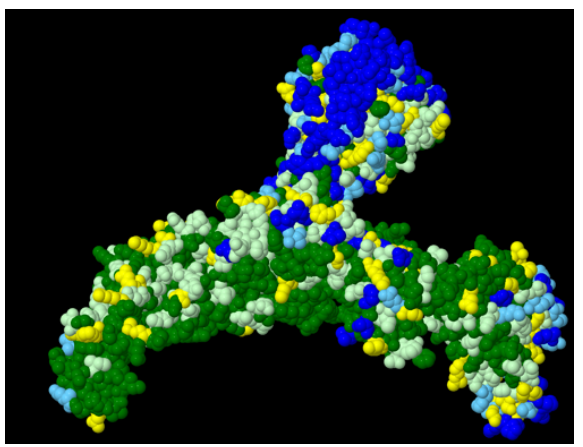

E

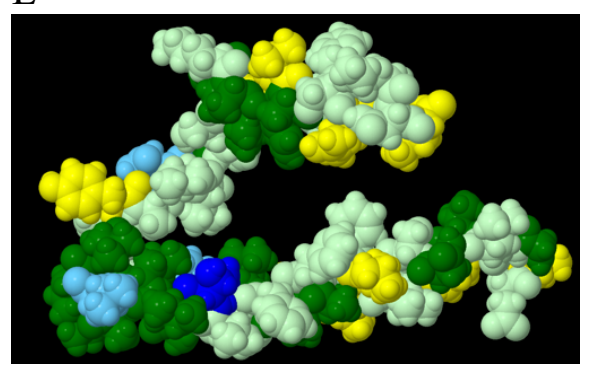

ORF7a
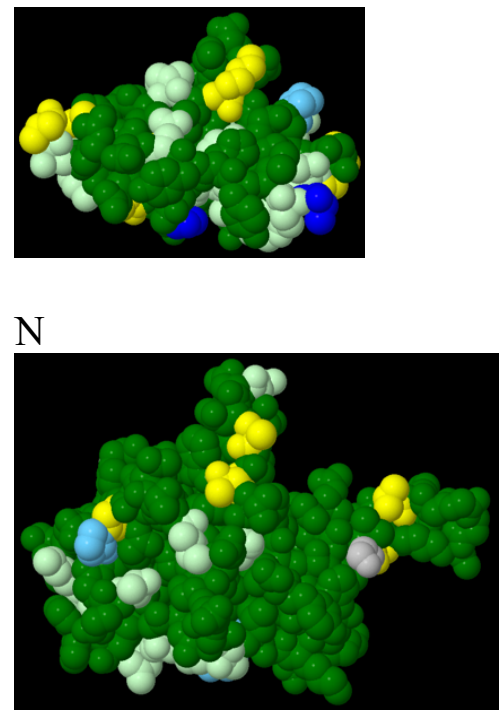
Figure 3. SARS-COV-1 Inhibitory Peptides N4643, HR1-142, HR2-1842, WW-III136, WW-IV136, SHR2-245, SHR2845, $\mathrm{HRC1}^{87}, \mathrm{HRC2}^{87}, \mathrm{CP}-1^{137}, \mathrm{SR9}{ }^{138}, \mathrm{P}^{43}$, and $\mathrm{CB}-11^{44}$. SARS-COV-2 residues different from SARS-CoV1 are underlined for adapting SARS-COV-1 inhibitory peptides.

SARS2 907-NGIGVTQNVLYENQKLIANQFNSAIGKIQDSLSSTASALGKLQDVVNQNAQALNTLVKQ-965

SARS1 889-NGIGVTQNVLYENQKQ̄IANQFNKAISQIQESLTTTSTALGKLQDVVNQNAQALNTLVKQ-947

N4 6 QKQIANQFNKAISQIQESLTTTSTALGKLQDVVNQNAQALNTLVKQ

HR1-1 NGIGVTQNVLYENQKQIANQFNKAISQIQESLTTTSTA

SARS2 1046-GYHLMSFPQSAPHGVVFLHVTY-1067

SARS1 1028-GYHLMSFPQÄAPHGVVFLHVTY-1049

WW-III GYHLMSFPQAAPHGVVFLHVTW-

SARS2 1093-GVFVSNGTHWFVTQRNFYE-1111

SARS1 1075-GVFVF'NGTSWFITQRNFFS-1093

WW-IV GVFVFNGTSWFITQRNFFS

SARS2 1144-ELDSFKEELDKYFKNHTSPDVDLGDISGINASVVNIQKEIDRLNEVAKNLNESLIDLQELGKYEQYIK-1211

SARS1 1126-ELDSFKEELDKYFKNHTSPDVDLGDISGINASVVNIQKEIDRLNEVAKNLNESLIDLQELGKYEQYIK-1193

SHR2-8

SHR2-2

HR2 -18

HRC2

ELDSFKEELDKYFKNHTSPDVDLGDISGINASVVNIQKEIDRLNEVAKNLNESLIDLQELGKYEQYIK

PKEELDKYFKNHTSPDVDLGDISGINASVVNIQKE IDRLNEVAKNLNESLIDLQELGKYE IQKEIDRLNEVAKNLNESLIDLQELGK QKEIDRLNEVIKNLNESIIDLQEL

$\mathrm{CP}-1$ NASIVNLQKEIDRLNEVIKNLNES

SR9

CB-119

GINASVVNIQKEIDRLNEVAKNLNESLIDLQELGKYE

GINASVVNIQKEIDRLNEVAKNL

ISGINASVVNIQKEIDRLNEVAKNLNESLIDLQEL

SPDVDLGDISGINAS 
